\title{
Prevalence of Hematuria among Emergency Department Healthcare Workers
}

\author{
Ho-Hsing Lin1, Chi-Wen Juan1,2*, Li-Ya Lin"3,4, Chi-Wei Lee5, Chien-Jen Huang6 \\ ${ }^{1}$ Department of Emergency Medicine, Kuang-Tien General Hospital, Taichung, Taiwan \\ ${ }^{2}$ Department of Nursing, Hungkuang University, Taichung, Taiwan \\ ${ }^{3}$ Centre for Environment and Population Health, Griffith University, Nathan, Australia \\ ${ }^{4}$ Department of Nursing, Kaomei Jounior College of Health Care and Management, Kaohsiung, Taiwan \\ ${ }^{5}$ Department of Emergency Medicine, Kaohsiung Medical University Hospital, Kaohsiung, Taiwan \\ ${ }^{6}$ Department of Occupational Safety and Health, Kuang-Tien General Hospital, Taichung, Taiwan \\ Email: ${ }^{*}$ juanchiwen@yahoo.com.tw
}

Received 10 July 2014; revised 9 August 2014; accepted 8 September 2014

Copyright (C) 2014 by authors and Scientific Research Publishing Inc.

This work is licensed under the Creative Commons Attribution International License (CC BY).

http://creativecommons.org/licenses/by/4.0/

(c) (i) Open Access

\section{Abstract}

Background: In Taiwan, emergency departments are so busy that it is not uncommon for staffs (doctors and nurses) to be deprived of their lunch breaks or breaks to go to the restroom. As a consequence, during their busy shifts some emergency department healthcare workers choose to limit their water intake and no time to micturate which are both risk factors of urinary tract infection or urolithiasis. Hematuria is a common laboratory finding due to urinary tract infection and urolithiasis. Objective: To assess the prevalence of hematuria among the emergency department healthcare workers, we conducted a retrospective study in a district hospital in Taiwan. Documented data included those of healthcare workers who worked in the emergency department, as well as other departments of the same hospital. Methods: We reviewed the three-year records of general body checkup of hospital staffs who served in the emergency room and other departments of the same hospital between January 1, 2009 and December 31, 2011. Statistical software SPSS statistical analysis of survey data recovery is applied; data and test results by the questionnaire analysis patterns are associated with the urinary system abnormalities to ANOVA analysis to explore the hospital group whether there is a significant sex differences, and the other to analyze and verify the correlation analysis to the Scheffe post-hoc comparison method. Results: A higher prevalence of hematuria was observed among emergency department healthcare workers when compared with their colleagues who work in other departments of the same hospital. Female workers have higher risk of urinary system abnormalities than male workers. Nurses in the urinary system abnormalities are higher than other positions category. Shift work system has a negative effect on the urinary system. Conclusion: In conclusion, hematuria is more prevalent among emergency department healthcare workers than healthcare workers working in the inpa-

\footnotetext{
${ }^{*}$ Corresponding author.
} 
tient wards. Hematuria might well be due to urinary tract infection which in turns caused by the overwhelmingly busy nature of the emergency department duty that deprived the emergency department healthcare workers from frequent voiding and sufficient intake of fluid.

\title{
Keywords
}

\author{
Hematuria, Emergency Department, Healthcare Workers
}

\section{Introduction}

Although an emergency department (ED) healthcare worker himself/herself may be well aware of the need to use the restroom, the thought may pass quickly due to his/her being busy and involved in the ED. ED healthcare workers here in Taiwan have a job that keeps them extremely busy throughout the day. ED doctors and nurses seldom get any official breaks during their shifts, not even for lunch but also for restroom use. Infrequent voiders syndrome, also referred to as nurses bladder, is supposed to be elicited by habitual suppression of the desire to void over a longer period of time [1]. The frequency of micturition was higher during evening and night shifts than in the day shift which could be a result of increased fluid intake or reduced work load [2]. It has been suggested that the resulting over distension of the bladder muscle damages bladder sensation and increases the bladder capacity. Infrequent voiders syndrome may provoke acute urinary retention and induce recurrent urinary infections. Main reasons for suppression of desire to void were busy work, poor toilet facilities and indolence [1]. Because ED doctors and nurses are bad to put off their patients' needs that should be taken care of, using the restroom and drinking lots of fluids. It seems obvious that holding back urine and urine tract infections are common in the ED healthcare profession [3]. Subsequent interventional studies such as moving some emergency nurses to ward or reducing their workload show a significantly lower prevalence level of urine tract infections. The majority of urinary tract infection victims are female. Hematuria is a common laboratory finding due to urinary tract infection and urolithiasis [1] [4] [5]. In this study we tried to compare the prevalence of hematuria in healthcare workers working in the ED with those who worked in other departments of the same hospital in order to highlight this particular underlying problem of ED in Taiwan.

\section{Method}

The study took place in a busy ED of a district hospital serving the population of Taichung city downtown and its sub-urban area. We collected data retrospectively from the three-year records of annual body checkup of hospital staffs who served in the emergency room and other departments between January 1, 2009 to December 31, 2011. The examination holds every 3 years. Totally 835 hospital staffs, 212 male and 623 female were included in this study. Among these subjects, 504 of them were younger 40 years of age and 331 were over 40 years of age. Their occupations in the hospital are 26 physicians, 434 nurses, 163 medical technicians, and 212 administrative staff. We focused upon the findings of the urine routine tests of each participant. The prevalence of hematuria of healthcare workers working in the ED was compared with the prevalence of hematuria of hospital staffs working in the other departments of the same hospital.

Data about these subjects' basic information, including: the past five years disease medical history, smoking, drinking habits, exercise and burnout scale, are collected by means of questionnaires. Each subject inspection measure microscopic hematuria, proteinuria, creatinine, blood pressure, height and weight (calculated BMI), cholesterol, fasting blood glucose and triglycerides. The burnout scale is used as the simple Chinese Version of Copenhagen Burnout Inventory, a single scale by the Council of Labor Affairs, divided into "personal burnout," and "work burnout," two dimensions of 13 questions which can be measured time of about 5 minutes. Personal burnout (Questions 1-6) is a state of prolonged physical and psychological exhaustion. Work burnout (Questions 7-13) is a state of prolonged physical and psychological exhaustion, which is perceived as related to the person's work.

Questions:

1) How often do you feel tired?

2) How often are you physically exhausted? 
3) How often are you emotionally exhausted?

4) How often do you think: "I can't take it anymore"?

5) How often do you feel worn out?

6) How often do you feel weak and susceptible to illness?

7) Is your work emotionally exhausting?

8) Do you feel burnt out because of your work?

9) Does your work frustrate you?

10) Do you feel worn out at the end of the working day?

11) Are you exhausted in the morning at the thought of another day at work?

12) Do you feel that every working hour is tiring for you?

13) Do you have enough energy for family and friends during leisure time?

In this study, statistical software SPSS statistical analysis of survey data recovery, data and test results by the questionnaire analysis patterns associated with the urinary system abnormalities to ANOVA analysis to explore the hospital group (job category) whether there is a significant sex differences, and the other to analyze and verify the correlation analysis to the Scheffe post-hoc comparison method "lowest and highest satisfaction of various dimensions of the various questions of demographic variables ANOVA analysis”.

\section{Result}

\subsection{The Whole Abnormal Urinalyses Ratio (Table 1)}

The results showed in the 835 subjects are: 183 (21.9\%) with microscopic hematuria, 36 (4.3\%) proteinuria, the results that both were positive in 25 (3.0\%). The male staff hematuria rate is $17.5 \%$ (abnormal males $37 / 212$ male subjects), the female staff hematuria rate is 23.4\% (abnormal females 146/623 female subjects). All 434 subjects nurses, there are 118 abnormal urinalyses, including intensive care units 15 (12.7\%), clinics 14 (11.9\%), emergency unit 13 (11.0\%), and operating rooms $11(9.3 \%)$ together accounted for $45 \%$, a significant trend in high abnormal urinalyses. Emergency unit has 26 subjects (10 male doctors and 16 female nurses), total of 10 people (38.5\%) with hematuria, higher than the average of all subjects abnormal rate (21.9\%). Display nearly 2 times the emergency units higher than the general staff of the abnormal urinalyses risk $(\mathrm{P}<0.05)$.

Emergency unit male doctor hematuria ratio was 2 (20\%), all of occult blood in urine male subjects was $17.5 \%$, no difference. But emergency unit female nurses hematuria ratio was $8(50 \%)$, much higher than the hospital all female subjects urine occult blood ratio (23.4\%), and in all categories of nurse urinary occult blood care (27.2\%) the highest.

Results of stress measurement: scores as shown in Tables 2-4.

All subjects were an average score 47.49 of the personal burnout dimension, 50 points or less, indicating that the overall staff's personal burnout are of minor extent, nursing staff 54.17 is the highest, falls within the scope of moderate stress level (50 - 70 points).

Table 1. The whole abnormal urinalyses ratio.

\begin{tabular}{|c|c|c|c|}
\hline & Hematuria & Proteinuria & Both \\
\hline Male number 212 & 37 (17.5\%) & $9(4.2 \%)$ & $3(1.4 \%)$ \\
\hline Female number 623 & $146(23.4 \%)$ & $27(4.3 \%)$ & $22(3.5 \%)$ \\
\hline Total number 835 & 183 (21.9\%) & $36(4.3 \%)$ & $25(3.0 \%)$ \\
\hline
\end{tabular}

Table 2. Average burnout score in the dimensions of personal and work.

\begin{tabular}{|c|c|c|c|}
\hline & Dimension & Personal burnout & Work burnout \\
\hline \multirow{5}{*}{$\begin{array}{c}\text { Category } \\
\text { of personnel }\end{array}$} & Nurses & $54.17 \pm 18.86$ & $45.73 \pm 16.89$ \\
\hline & Physicians & $43.68 \pm 16.53$ & $36.37 \pm 16.25$ \\
\hline & Medical technicians & $40.84 \pm 15.39$ & $32.67 \pm 15.10$ \\
\hline & Administrative staff & $39.32 \pm 16.72$ & $32.56 \pm 15.56$ \\
\hline & Overall average score & $47.49 \pm 18.85$ & $39.05 \pm 17.22$ \\
\hline
\end{tabular}


Table 3. The lowest satisfaction of each dimension of the questions of the demographic variables ANOVA analysis results.

\begin{tabular}{cccc}
\hline & Dimension & Personal burnout & Work burnout \\
\hline Nurses & & \\
$\begin{array}{c}\text { Category } \\
\text { of personnel }\end{array}$ & $\begin{array}{c}\text { Physians } \\
\text { Medical technicians } \\
\text { Administrative staff }\end{array}$ & $\mathrm{F}(1,3)=74.62, \mathrm{P}<0.01$ & $\mathrm{~F}(1,3)=63.74, \mathrm{P}<0.01$ \\
& & & \\
\hline
\end{tabular}

Table 4. The highest satisfaction of each dimension of the questions of the demographic variables ANOVA analysis Scheffe post-hoc comparison method.

\begin{tabular}{ccccc}
\hline & Dimension & Number of subject & Personal burnout (\%) & Work burnout (\%) \\
\hline \multirow{4}{*}{$\begin{array}{c}\text { Category } \\
\text { of personnel }\end{array}$} & Nurses & 434 & 54.17 & 45.73 \\
& Physicians & 26 & 43.68 & 36.67 \\
& Medical technicians & 163 & 40.84 & 32.67 \\
& Administrative staff & 212 & 39.32 & 32.56 \\
\hline
\end{tabular}

All subjects were an average score 39.05 of the work burnout dimension, below 45 points shows the overall extent for the work burnout were classified as minor, nursing staff 45.73 is the highest, falls within the scope of moderate stress level (45 - 60 points).

The results of different job categories that individual significant differences related to burnout scores, $\mathrm{F}(1,3)$ $=74.62, \mathrm{P}<0.01$, post hoc comparisons show "Nurses" categories: 54.17 points significantly greater than "Physicians" category 43.68 points, "Medical technicians" category 40.84 points, "Administrative staff” 39.32 points. Different categories of work-related duties are significant differences in burnout scores, $\mathrm{F}(1,3)=63.74, \mathrm{P}<$ 0.01 , post hoc comparisons show significant nurses class 45.73 points greater than the "Physicians" 36.67 points, "Medical technician” 32.67 points, “Administrative staff” 32.56 points.

\subsection{Difference in "Gender"}

Male subjects in 37 microscopic hematuria (17.5\%), 9 proteinuria (4.2\%), both were positive in 3 (1.4\%); female subjects were 146 microscopic hematuria (23.4\%), 27 proteinuria (4.3\%), both were positive in 22 (3.5\%). T-test results in the male and female gender dimensions of $\mathrm{P}<0.05$ show significant differences, and that female workers have higher risk of urinary system abnormalities than male.

\subsection{Categorical Variables and Variance Analysis}

We will post categories into physician, nursing, medical technology and administrative staff by SPSS for oneway ANOVA test, and then by post hoc multiple comparisons to Scheffe analysis showed that nurses in the urinary system abnormalities is higher than other positions category and there is a statistically significant difference, $\mathrm{P}=0.004$. In the shift and non-shift effect of the urinary system abnormalities in T-test for each dimension variance analysis, $\mathrm{P}$ value of 0.021 is less than 0.05 , the results showed a significant difference. From the above test results, "shift" work system has a negative effect on the urinary system.

\section{Discussion}

The typical emergency department (ED) shift is not only cognitively demanding, requiring complex decision making in a fast-paced environment, but is also physically demanding. During a regular shift, ED physicians and nurses may be far removed from areas that provide access to fluids. So they are often unable to drink properly or at all during their shifts; especially in warm countries, this can lead to increased perspiration and higher water requirements [6]. EDs here in Taiwan are also overwhelmingly busy that it is common for staffs (doctors and nurses) to be deprived of their lunch breaks or even breaks to go to the restroom. As a result, during their busy shifts some ED healthcare workers choose to limit their water intake and try not to micturate. Unfortunately, both of these are risk factors of urinary tract infection or urolithiasis [7]-[9].

Hematuria is a common laboratory finding due to urinary tract infection and urolithiasis. The reason why 
there are red blood cells in urine when there is a urinary tract infection lies in the fact that the inflammatory response is taking place. Urinary tract infection is infection that occurs anywhere in the urinary system (kidney, ureters, bladder, urethra). The inflammatory response occurs along with all infections. Mast cells at the site of infection rupture and release histamine which causes the blood vessels in the surrounding area to dilate and increases their permeability. This results in the escape of some red blood cells and white blood cells into the urine, particularly when the infection has affected the ureters, bladder, and/or urethra. The results of the actions of histamine are the cardinal signs of inflammation: redness, heat, swelling and pain. Hematuria is a secondary effect because of the blood vessel dilation and permeability. It was reported that the presence of hematuria and/or urgency as symptoms of first urinary tract infection was the strongest predictor of second infection [10].

In fact, ED healthcare workers face serious health problems due to the lack of time for immediate and regular access to restroom facilities. Overwhelming loadings and patients' demands too often force ED doctors and nurses, to either "hold it" when they need to use a restroom, or to refrain from eating or drinking fluids for long periods of time in order to avoid the need to use a restroom [11]. These actions can result in serious health problems and safety hazards to their patients. To avoid these, ED healthcare workers are strongly encouraged to stay well-hydrated and to take restroom breaks as needed. Medical studies show the importance of regular urination. These studies also show that women generally need to void more frequently than men but that there are health hazards for both sexes. The most common adverse health effect that may result from voluntary urinary retention is urinary tract infection, which was reflected in the higher prevalence of hematuria in this study [3].

Furthermore, voluntary urine retention can also represent a safety hazard to the ED patients since an ED doctor or nurse who is forced to "hold it" is distracted and more likely to make clinical mistakes. The dehydration resulting from refraining from drinking can cause an ED healthcare worker to lose focus, become dizzy or distracted, posing a serious safety hazard to the ED patients they care [12]. Previous studies have demonstrated that proper hydration plays a significant role in human performance and dehydration as low as $2 \%$ of the body weight has been shown to adversely influence decision-making and cognitive performance, which could be associated with an increased risk of work-related accidents [13]. The majority of physicians and to a lesser extent nurses working in a tertiary care emergency department have decreased hydration status at the end of the shift. Therefore, awareness of the hydration status by emergency department staff is needed [6].

One may claim that ED doctors and nurses can take a restroom break whenever they need one, even if it interrupts the course of patient-care. Despite this, ED healthcare workers often forgo restroom breaks due to their concerns about angering or endangering their ED patients, facing subtle medicolegal disputes for delay, and embarrassment over having to request a restroom break to their patients and colleagues.

Limitations of this study include its retrospective approach, single-hospital nature and small sample size. Being a case-series report, it plays a good role as a hypothesis generator, yet fails to generalize its clinical findings due to the lack of control group (low evidence level). In a more convincing evidence-based manner, further prospective multiple-center research should focus on proving the causative role of ED healthcare workers' urinary tract infection due to overloading of their job.

Due to the limitations of this study, further large-scale longitudinal study is needed to clarify the relationship between the types of occupation in the hospital and the urinary tract abnormalities. According to this three-year study, we conclude that a number of risk factors for urinary system diseases, including:

1) The female gender;

2) Shifting duty;

3) Long continuous working hours;

4) Lack of exercise;

5) Insufficient intake of water;

6) Personal hygiene.

Shifting duties in hospitals are inevitable. Increasing number of studies point out the negative impact of such working patterns. It is highly recommended that improvement in the management and arrangement of the shifting system should focus on the development of good exercise and eating habits, the establishment of a good working environment to reduce occupational injuries, the improvement of sleeping patterns, in order to prevent potential hazards of shifting duties [14].

After conducting this study, the study hospitals, nursing department now provide "tea time", according to the nature of their services to design their schedules, at least once per shift for "drinking", and "toileting" time to avoid personnel due to continuous operation time is too long, causing the occurrence of abnormal urinalyses. 
Brake et al. reported that individuals working in a thermally stressful environment were better able to maintain hydration when they were educated about dehydration, assessed their hydration state and used a fluid replacement program while working [15]. Education is a vital component to help workers maintain their hydration state during and after a work shift. Informing individuals, especially those who work in EDs, about hydration assessment, signs and dangers of dehydration, and strategies to maintain hydration while working can reduce dehydration in the workplace. One recommendation that may enhance hydration at the work site involves improving access to bathroom facilities, particularly women, will purposefully not drink fluids when bathroom facilities are not available. Providing access may be a simple means of improving workplace hydration and reducing the practice of voluntary dehydration [6].

\section{Conclusion}

Working stress in medical institutions is enormous (especially among nursing staff), and as "shifting-duty" is a mandatory working pattern in nursing, thereby affecting personal habits of the healthcare workers and resulting in a serious shortage of exercise, proper hydration, adequate rest, available bathroom, as well as an impact of "urinary system diseases". The results of this study provide supporting evidence for the close relationship between working patterns and urinary system diseases.

\section{References}

[1] Bendtsen, A.L., Andersen, J.R. and Andersen, J.T. (1991) Infrequent Voiders Syndrome (Nurses Bladder). Prevalence among Nurses and Assistant Nurses in a Surgical Ward. Scandinavian Journal of Urology and Nephrology, 25, 201204. http://dx.doi.org/10.3109/00365599109107947

[2] Sugaya, K., Nishijima, S., Oda, M., Owan, T., Miyazato, M. and Ogawa, Y. (2008) Biochemical and Body Composition Analysis of Nocturia in the Elderly. Neurourology and Urodynamics, 27, 205-211. http://dx.doi.org/10.1002/nau.20492

[3] Mangaoang, H.L.E. (2011) Renal Health Advocacy for Nurses in La Union: A Prototype. E-International Scientific Research Journal, 3, 34-46.

[4] Hooton, T.M., Scholes, D., Hughes, J.P., Winter, C., Roberts, P.L., Stapleton, A.E., Stergachis, A. and Stamm, W.E. (1996) A Prospective Study of Risk Factors for Symptomatic Urinary Tract Infection in Young Women. New England Journal of Medicine, 335, 468-474. http://dx.doi.org/10.1056/NEJM199608153350703

[5] Chung, A., Arianayagam, M. and Rashid, P. (2010) Bacterial Cystitis in Women. Australian Family Physician, 39, 295-298.

[6] Alomar, M.Z., Akkam, A., Alashqar, S. and Eldali, A. (2013) Decreased Hydration Status of Emergency Department Physicians and Nurses by the End of Their Shift. International Journal of Emergency Medicine, 6, 27. http://dx.doi.org/10.1186/1865-1380-6-27

[7] Hsieh, C.H., Chen, H.Y., Hsu, C.S., Chang, S.T. and Chiang, C.D. (2007) Risk Factors for Nocturia in Taiwanese Women Aged 20-59 Years. Taiwanese Journal of Obstetrics \& Gynecology, 46, 166-170. http://dx.doi.org/10.1016/S1028-4559(07)60012-6

[8] Hsieh, C.H., Chen, H.Y., Hsu, C.S., Chang, S.T., Kuo, T.C. and Chiang, C.D. (2006) Risk Factors for Urinary Frequency in Taiwanese Women Aged 20-59 Years. Taiwanese Journal of Obstetrics \& Gynecology, 45, 329-332. http://dx.doi.org/10.1016/S1028-4559(09)60253-9

[9] Hsieh, C.H., Lee, M.S., Lee, M.C., Kuo, T.C., Hsu, C.S. and Chang, S.T. (2008) Risk Factors for Urinary Incontinence in Taiwanese Women Aged 20-59 Years. Taiwanese Journal of Obstetrics \& Gynecology, 47, 197-202. http://dx.doi.org/10.1016/S1028-4559(08)60080-7

[10] Foxman, B. (1990) Recurring Urinary Tract Infection: Incidence and Risk Factors. American Journal of Public Health, 80, 331-333. http://dx.doi.org/10.2105/AJPH.80.3.331

[11] Nygaard, I. and Linder, M. (1997) Thirst at Work-An Occupational Hazard? International Urogynecology Journal and Pelvic Floor Dysfunction, 8, 340-343. http://dx.doi.org/10.1007/BF02765593

[12] Palmer, M.H., Athanasopoulos, A., Lee, K.S., Takeda, M. and Wyndaele, J.J. (2012) Sociocultural and Environmental Influences on Bladder Health. International Journal of Clinical Practice, 66, 1132-1138. http://dx.doi.org/10.1111/ijcp.12029

[13] Szinnai, G., Schachinger, H., Arnaud, M.J., Linder, L. and Keller, U. (2005) Effect of Water Deprivation on CognitiveMotor Performance in Healthy Men and Women. American Journal of Physiology-Regulatory, Integrative and Comparative Physiology, 289, 275-280. http://dx.doi.org/10.1152/ajpregu.00501.2004 
[14] Suwazono, Y., et al. (2005) Long-Term Longitudinal Study on the Relationship between Alternating Shift Work and the Onset of Diabetes Mellitus in Male Japanese Workers. Journal of Occupational and Environmental Medicine, 48, 455-461. http://dx.doi.org/10.1097/01.jom.0000214355.69182.fa

[15] Brake, D.J. and Bates, G.P. (2003) Fluid Losses and Hydration Status of Industrial Workers under Thermal Stress Working Extended Shifts. Occupational and Environmental Medicine, 60, 90-96. http://dx.doi.org/10.1136/oem.60.2.90 
Scientific Research Publishing (SCIRP) is one of the largest Open Access journal publishers. It is currently publishing more than 200 open access, online, peer-reviewed journals covering a wide range of academic disciplines. SCIRP serves the worldwide academic communities and contributes to the progress and application of science with its publication.

Other selected journals from SCIRP are listed as below. Submit your manuscript to us via either submit@scirp.org or Online Submission Portal.
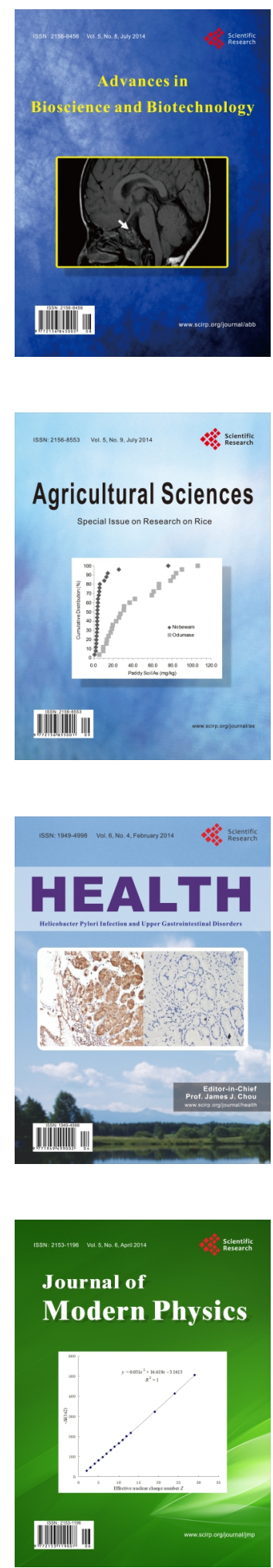
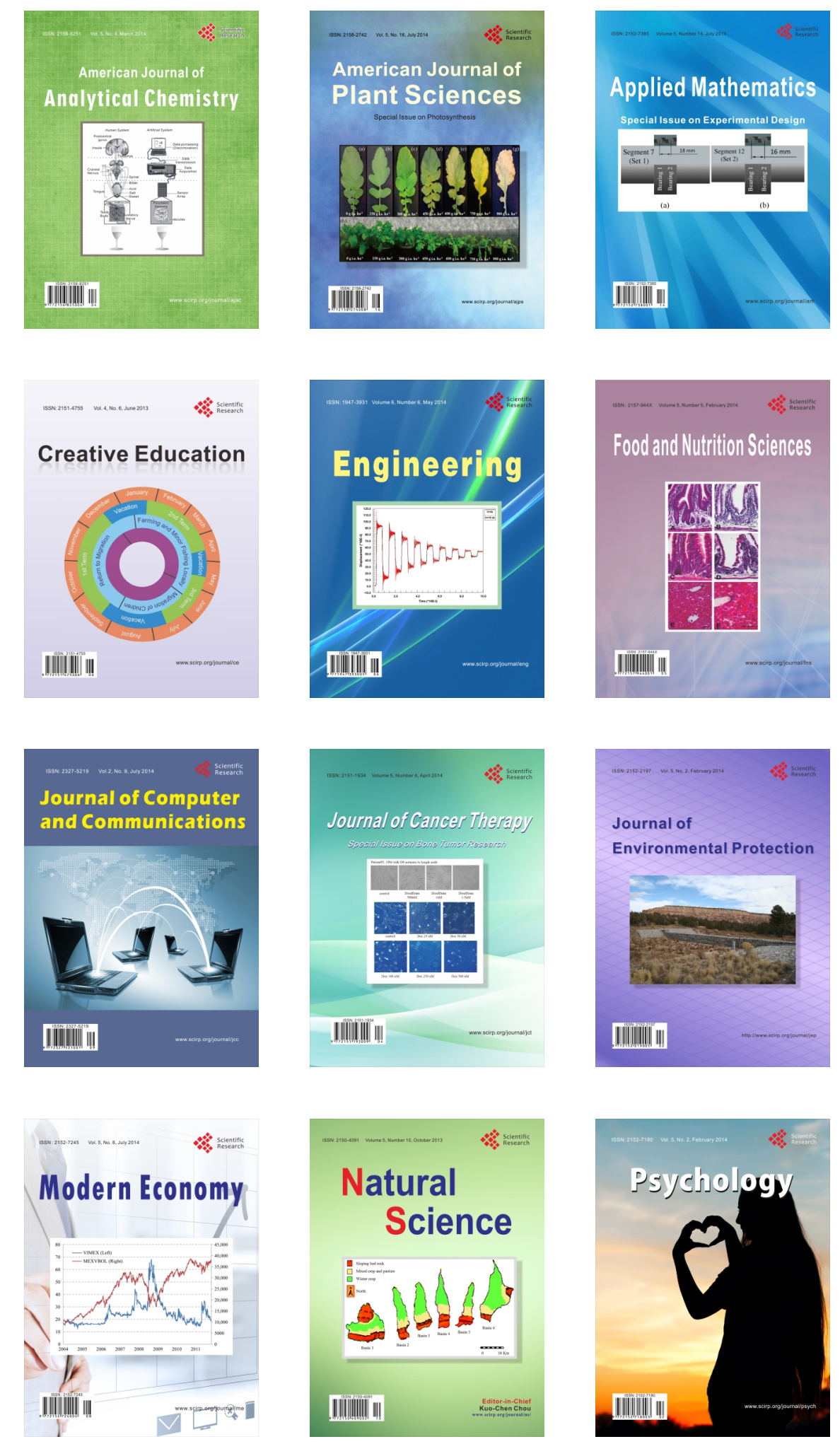